\title{
Acute myelitis with hyperIgEaemia and mite antigen specific IgE: atopic myelitis
}

\author{
Jun-ichi Kira, Yuji Kawano, Kenji Yamasaki, Shozo Tobimatsu
}

\begin{abstract}
An occurrence of acute localised myelitis was recently seen in four adult patients with atopic dermatitis who had hyperIgEaemia and mite antigen specific IgE. The total and mite antigen specific IgE was therefore studied in serum samples from 19 consecutive patients with acute localised myelitis of unknown aetiology, 56 patients with clinically definite multiple sclerosis, and 40 healthy controls. The total IgE concentration was significantly higher in acute localised myelitis (median $=360 \mathrm{U} / \mathrm{ml}$ ) than in multiple sclerosis (median $=52 \mathrm{U} / \mathrm{ml}, \mathrm{p}<0.0001$ ) and the controls (median $=85 \mathrm{U} / \mathrm{ml}, p=0.0002$ ). The specific IgE to Dermatophagoides pteronyssinus was found more often in patients with acute localised myelitis (95\%) than in patients with multiple sclerosis $(34 \%$, $\mathbf{p}<0.0001)$ and the controls $(35 \%$, $\mathbf{p}<0.0001)$ and the specific IgE to Dermatophagoides farinae was similar (acute localised myelitis $79 \%$, multiple sclerosis $29 \%(p<0.0001)$, controls $30 \%,(p=0.0003)$. Atopic dermatitis coexisted more commonly in patients with acute localised myelitis $(37 \%)$ than in patients with multiple sclerosis $(0 \%, \mathrm{p}<0.0001)$ and the controls $(7.5 \%, p=0.0089)$. Therefore, acute localised myelitis with hyperIgEaemia, in which atopy to mite antigens seems to exist, may be a distinct subtype of allergic myelitis-that is, atopic myelitis.
\end{abstract}

(F Neurol Neurosurg Psychiatry 1998;64:676-679)

Neurophysiology,

Neurological Institute,

Faculty of Medicine,

Kyushu University

J Kira

Y Kawano

K Yamasaki

S Tobimatsu

Correspondence to: Professor Jun-ichi Kira, Department of Neurology, Neurological Institute, Faculty of Medicine, Kyushu University 60 , Fukuoka 812-82, Japan.

Received 1 September 1997 and in revised form 7

November 1997

Accepted 19 November 1997

Keywords: myelitis; hyperIgEaemia; mite antigen specificity

Atopy is defined as an enhanced IgE responsiveness to such common environmental antigens as pollens, foods, and house dust mites. ${ }^{1}$ Atopic disorders are common in childhood, and the number of adult patients with atopic disorders is now increasing in many industrialised countries. ${ }^{2}$ Although neither atopic disorders nor hyperIgEemia have previously been shown to be associated with myelitis, we recently found four adult patients with acute myelitis who all had hyperIgEaemia and mite antigen specific IgE as well as atopic dermatitis. ${ }^{3}$ The existence of such patients prompted us to study the total and mite antigen specific IgE in acute myelitis.

\section{Subjects and methods}

SUBJECTS

Nineteen consecutive patients, who showed an acute onset of monophasic spinal cord syndrome which was well defined rostrally (acute localised myelitis) and were subjected to a thorough neurological examination and routine laboratory tests between July 1992 and June 1997, were enrolled in the present study. No specific cause was identified in any. None of the patients developed a clear cut relapse during the follow up period (mean (SD) 23 (SD 19) months). Patients with acute disseminated encephalomyelitis, who clinically showed disseminated or multiple involvement of the CNS in addition to that of the spinal cord, were excluded. As controls, 56 patients with clinically definite multiple sclerosis, ${ }^{4}$ who were followed up at our multiple sclerosis clinic during the same period, were used. In addition, 40 healthy hospital workers, 20 men and 20 women, were used as controls. The disability of the patients was evaluated using the Kurtzke's expanded disability status scale (EDSS). ${ }^{5}$ The age at examination was 34 (SD 12) years in the patients with acute localised myelitis, 41 (SD 11) years in the patients with multiple sclerosis, and 34 (SD 8) years in the controls. None of the subjects had antiHTLV-I antibody.

\section{ASSAY FOR TOTAL AND MITE ANTIGEN SPECIFIC} IgE
The total and allergen specific IgE in the serum were measured by an enzyme linked immunosorbent assay (ELISA). ${ }^{3}$ Two mite antigens, Dermatophagoides farinae and Dermatophagoides pteronyssinus, cedar pollen, candida, egg white, milk, wheat, rice, and soybean were used as allergens for ELISA (AlaSTAT, Sankojunyaku, Tokyo, Japan). The total and mite antigen specific IgE were measured in all subjects, and the specific IgE to other allergens was measured in hyperIgEaemic patients with acute localised myelitis. The patients with a serum IgE concentration $>250 \mathrm{U} / \mathrm{ml}$ were considered to have hyperIgEaemia according to the 
Clinical-laboratory findings in the19 myelitic patients with or without hyperIgEaemia

\begin{tabular}{|c|c|c|}
\hline & $\begin{array}{l}\text { HyperIgEaemia } \\
(n=12)\end{array}$ & $\begin{array}{l}\text { NormoIgEaemia } \\
(n=7)\end{array}$ \\
\hline Sex ratio $(M: F)$ & $7: 5$ & $6: 1$ \\
\hline Age of onset (y) & 33 (SD 11) & 35 (SD 13) \\
\hline Atopic dermatitis & $7^{\star}$ & 0 \\
\hline \multicolumn{3}{|l|}{ Initial symptoms: } \\
\hline Numbness in limbs & 6 & 5 \\
\hline Weakness or clumsiness of limbs & 3 & 2 \\
\hline Others & 3 & 0 \\
\hline \multicolumn{3}{|l|}{ Symptoms and signs during illness: } \\
\hline Paraesthesia/dysaesthesia & 9 & 7 \\
\hline Increased deep reflex & 8 & 6 \\
\hline Sensory signs & 6 & 5 \\
\hline Sphincter disturbance & 5 & 2 \\
\hline Lhermitte's sign & 4 & 3 \\
\hline Motor weakness & 3 & 3 \\
\hline Babinski’s sign & 2 & 3 \\
\hline \multicolumn{3}{|l|}{ Clinically estimated main lesions: } \\
\hline Cervical cord & 9 & 3 \\
\hline Thoracic cord & 3 & 4 \\
\hline EDSS at peak & $2.5(0.9)$ & $3.1(2.1)$ \\
\hline EDSS at recovery stage & $0.75(0.6)$ & $1.4(1.0)$ \\
\hline \multicolumn{3}{|l|}{ CSF: } \\
\hline Pleocytosis $(>5 / \mu \mathrm{l})$ & $2^{\star}$ & 5 \\
\hline Increased protein $(>45 \mathrm{mg} / \mathrm{dl})$ & 1 & 3 \\
\hline \multicolumn{3}{|l|}{ Spinal cord MRI: } \\
\hline High signal intensity lesions on $\mathrm{T} 2$ & 6 & 4 \\
\hline Cervical cord & 5 & 2 \\
\hline Thoracic cord & 1 & 2 \\
\hline Gadolinium enhancement & 4 & 2 \\
\hline
\end{tabular}

${ }^{{ }^{*} \mathrm{p}<0.05}$.

preliminary control study. ${ }^{3}$ The cut off value for allergen specific $\mathrm{IgE}$ was $0.34 \mathrm{IU} / \mathrm{ml}^{3}{ }^{3}$

STATISTICAL ANALYSIS

The Mann-Whitney $U$ test was used for a statistical analysis of the total serum IgE concentration. Either the $\chi^{2}$ test or Fisher's exact test (when the criteria of the $\chi^{2}$ test was not fulfilled) was used for the analysis of the frequency of hyperIgEaemia, specific IgE to mite antigens, and other clinical-laboratory abnormalities.

\section{Results}

TOTAL AND ALLERGEN SPECIFIC IgE

The serum total IgE concentration was significantly higher in the patients with acute localised myelitis (median $=360 \mathrm{U} / \mathrm{ml}$ ) than in those with multiple sclerosis (median $=52$ $\mathrm{U} / \mathrm{ml}, \mathrm{p}<0.0001$ ) and in the healthy controls (median $=85 \mathrm{U} / \mathrm{ml}, \mathrm{p}=0.0002$ ). The frequency of hyperIgEaemia was also significantly higher in the patients with acute localised myelitis $(63 \%)$ than in those with multiple sclerosis $(18 \%, \mathrm{p}=0.0001)$ and in the healthy controls $(23 \%, \mathrm{p}=0.0025)$. Moreover, the patients with acute localised myelitis also showed a significantly higher frequency of mite antigen specific IgE than did those with multiple sclerosis $(D$ pteronyssinus, $95 \%$ v 34\%, $\mathrm{p}<0.0001$, and $D$ farinae, $79 \%$ v $29 \%, \mathrm{p}<0.0001)$ and the healthy controls ( $D$ pteronyssinus, $95 \%$ v $35 \%$, $\mathrm{p}<0.0001$, and $D$ farinae, $79 \%$ v $30 \%$, $\mathrm{p}=0.0003$ ). Atopic dermatitis more commonly coexisted at the time of neurological examination in the patients with acute localised myelitis $(37 \%)$ than in either the patients with multiple sclerosis $(0 \%, \mathrm{p}<0.0001)$ or the healthy controls $(7.5 \%, p=0.0089)$, whereas the frequency of coexisting allergic rhinitis and asthma did not differ significantly among the three groups $(16 \%$ and $0 \%$ in patients with acute localised myelitis, $11 \%$ and $0 \%$ in the patients with multiple sclerosis, and $23 \%$ and $2.5 \%$ in the controls). There was no significant difference between patients with multiple sclerosis and the controls for total serum IgE concentration, the frequency of mite antigen specific IgE and atopic dermatitis. In the 12 hyperIgEaemic patients with acute localised myelitis, all had specific IgE to D pteronyssinus
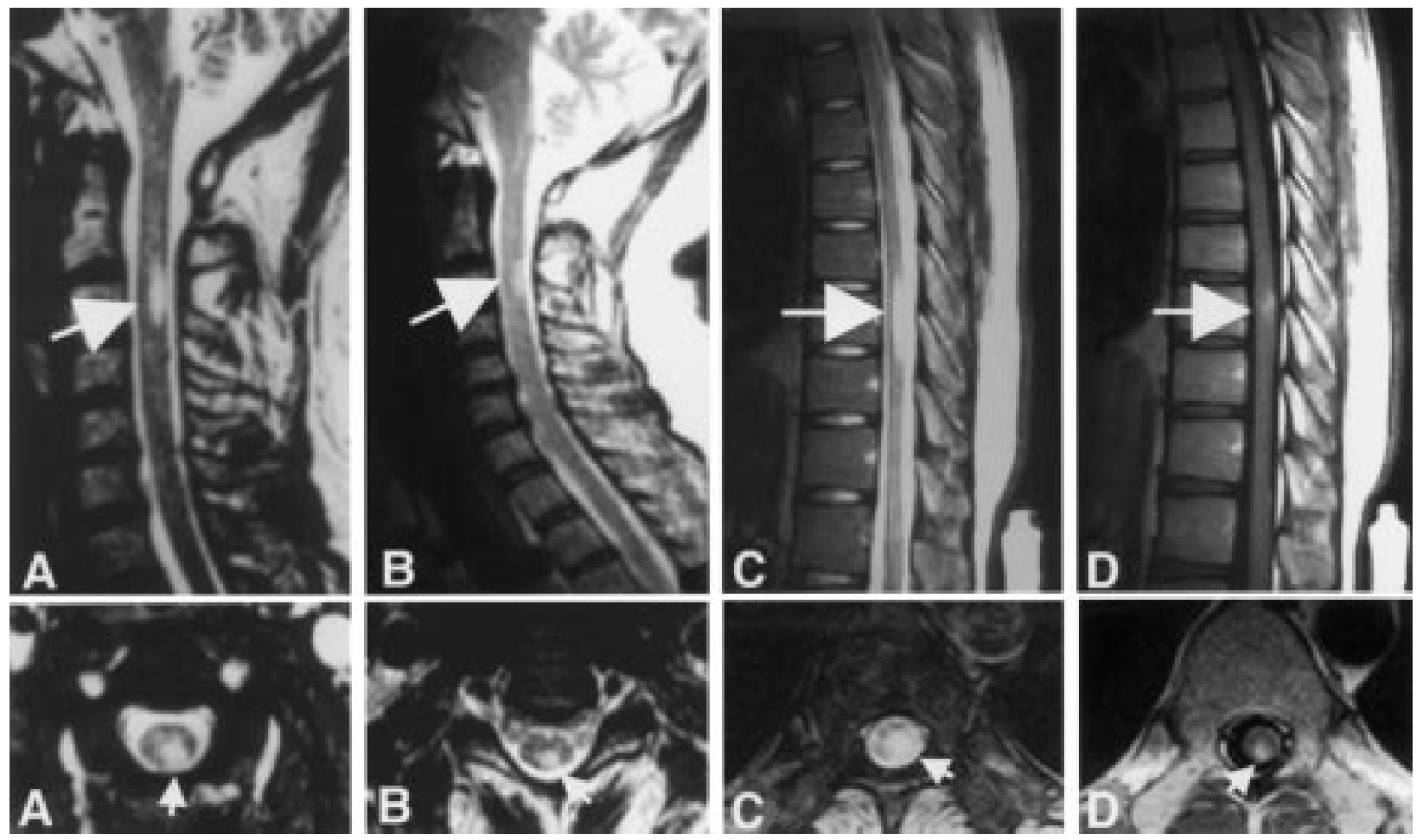

MRI of the spinal cord in patients with acute localised myelitis who had hyperIgEaemia and mite antigen specific IgE. T2 weighted images (A, B, $C$ ) and gadolinium enhanced $T 1$ weighted images (D) are shown. (A) shows two weeks and (B) shows six months after the onset of the neurological symptoms in a patient with atopic dermatitis. $(C)$ and $(D)$ are from a patient without atopic dermatitis. 
and 11 had specific IgE to $D$ farinae, whereas specific $\operatorname{IgE}$ to other common environmental antigens was found at much lower frequencies (five to cedar pollen, three to soybean, two to candida, wheat, and rice, and one to egg white and milk).

\section{CLINICAL-LABORATORY FINDINGS}

The clinical-laboratory findings were compared between the acute localised myelitis patients with and without hyperIgEamia (table). The frequency of atopic dermatitis was significantly higher in the hyperIgEaemic patients than in the normoIgEaemic patients $(p=0.0174)$. The frequency of female patients was higher in the hyperIgEaemic patients than in the normoIgEaemic patients ( $42 \% v 14 \%)$, but the difference did not reach significance, probably due to the small sample size. The age of onset, initial symptoms, symptoms and signs during illness, and the EDSS scores did not differ significantly between the two groups. However, in hyperIgEaemic patients, the cervical cord was three times more commonly affected than the thoracic cord, whereas in normoIgEaemic patients the thoracic cord was affected more often than the cervical cord.

The frequency of CSF pleocytosis was significantly lower in hyperIgEaemic patients than in normoIgEaemic patients $(17 \%$ v $71 \%$, $\mathrm{p}=0.0449)$. The increase in total protein was also found less often in hyperIgEaemic patients than in normoIgEaemic patients ( $8 \% v 43 \%)$, although this difference did not reach significance. None of the nine hyperIgEaemic patients examined showed either oligoclonal IgG bands or an increased IgG index.

Among the hyperIgEaemic patients who showed a high signal intensity lesion on T2 weighted images of the spinal cord, the lesion was located in the high cervical cord (C2-4) in all but one case (figure), whereas no such predilection to the high cervical cord was seen in the normoIgEaemic patients. The MRI lesions persisted for more than three months in four hyperIgEaemic patients $(4,13,16$, and 25 months), despite the benign clinical course. Only one of 10 hyperIgEaemic patients examined had subclinical lesions on brain MRI (several small lesions in the white matter).

\section{Discussion}

In the present study, a significant association of acute localised myelitis with both hyperIgEaemia and specific IgE antibody to mite antigens was found. An examination of specific IgE to other common allergens disclosed two mite antigens to be the main antigens for $\operatorname{IgE}$ responses in these patients. Moreover, hyperIgEaemic patients with acute localised myelitis showed the following distinct features: (1) a preferential involvement of the cervical cord, which was less often affected in the normoIgEaemic acute localised myelitis patients as well as in cases of acute transverse myelitis in the previous report, ${ }^{6}(2)$ a frequent coexistence of atopic dermatitis, (3) a high frequency of normal CSF findings including a normal IgG index and the absence of oligoclonal IgG bands, and (4) spot-like high signal intensity lesions preferentially affecting the high cervical cord on the spinal cord MRI.

Together with the clinical course, both the absence of an abnormal IgG response in CSF and rare brain lesions on MRI probably rule out the possibility of multiple sclerosis in our hyperIgEaemic patients. Furthermore, our study disclosed that neither the total serum IgE nor the frequency of mite antigen specific IgE increased in multiple sclerosis, which is consistent with the previous findings in white patients with multiple sclerosis. ${ }^{78}$ These findings thus suggest that acute localised myelitis with hyperIgEaemia might have been produced by an immunological mechanism distinct from multiple sclerosis.

In atopic disorders, both IgE and mast cells are known to play a central part. ${ }^{1910}$ The binding of allergens to mast cell bound IgE initiates the release of inflammatory mediators, which results in inflammation and the characteristic symptoms of atopic disorders. ${ }^{11}$ If mite antigen specific IgE antibodies possess some cross reactivity with CNS antigens, they may well initiate the breakdown of the blood-brain barrier through the binding between mast cells and the CNS antigens, as suggested in the case of IgE antibody to myelin basic protein in experimental allergic encephalomyelitis. ${ }^{11}$ Interestingly, both cutaneous mast cells and CNS mast cells are connective tissue type mast cells, ${ }^{12}$ whereas mucosal type mast cells exist in other sites affected by atopic disorders. The frequent coexistence of atopic dermatitis in our patients may therefore suggest an involvement of connective tissue type mast cells commonly present in the two target tissues-skin and the CNS.

Finally, we consider it important to recognise atopy to mite antigens as one of the potential causes of myelitis. Because acute localised myelitis with hyperIgEaemia has distinct features and atopy to mite antigens is considered to be one of the underlying factors of this condition, we propose the diagnostic term atopic myelitis for such patients.

This work was supported in part by grants from the Neuroimmunological Disease Research Committee, the Ministry of Health and Welfare of Japan, and from the Ministry of Education, Science, Sports and Culture of Japan (No 08670712).

1 Stenius B, Wide L, Seymour WM, et al. Clinical significance of specific IgE to common allergens. I. Relationship of specific IgE against Dermatophagoides spp and grass pollen to 2 Rothe MJ, Grant-Kels JM. Atopic dermatitis: an update. $\mathfrak{f}$ Am Acad Dermatol 1996;35:1-13.

3 Kira J, Yamasaki K, Kawano Y, et al. Acute myelitis associated with hyperIgEaemia and atopic dermatitis. $\mathcal{f}$ associated with hyperIgEaemia
Neurol Sci 1997;148:199-203.

4 Poser CM, Paty DW, Scheinberg L, et al. New diagnostic criteria for multiple sclerosis: guidelines for research protocols, Ann Neurol 1983;133:227-31.

5 Kurtzke JF. Rating neurologic impairment in multiple sclerosis: an expanded disability status scale (EDSS). Neurology 1983;33:1444-52.

6 Altrocchi PH. Acute transverse myelopathy. Arch Neurol 1963;9:111-9.

7 Ansari KM, Yokoyama MM, Rand A. Circulating IgE, allergy and multiple sclerosis: serum levels of IgE, other immunoglobulins and complement $\left(C^{\prime} 3\right)$ in patients with multiple sclerosis in exacerbation and other neurologic dismultiple sclerosis in exacerbation and other

8 Barsoum AL, Hoher PG, Kuwert EK. Serum immunoglobulin E level and search for myelin basic protein specific IgE antibodies in patients with multiple sclerosis. Med cific IgE antibodies in patients with $\mathrm{m}$
Microbiol Immunol 1977;163:227-32. 
9 Leung DYM. Atopic dermatitis: immunobiology and treatment with immune modulators. Clin Exp Immunol 1997; 107(suppl 1):25-30.

10 Moore MJ, Behan PO, Kies MW, et al. Reaginic antibody in experimental allergic encephalomyelitis. I. Characterization of heat-labile skin-fixing antibody. Res Commun Chem Patho Pharmacol 1974;9:119-32.

11 Katayama I, Tanei R, Yokozeki $\mathrm{H}$, et al. Induction of eczematous skin reaction in experimentally induced hyper- plastic skin of balb/c mice by monoclonal anti-DNP IgE antibody: possible implications for skin lesion formation in topic dermatitis. Int Arch Allergy Appl Immunol 1990;93: 148-54.

12 Johnson D, Yasui D, Seeldrayers P. An analysis of mast cell frequency in the rodent nervous system: numbers vary between different strains and can be reconstituted in mast cell-deficient mice. $\mathcal{F}$ Neuropathol Exp Neurol 1991;50:22734

\section{HISTORICAL NOTES}

\section{Early accounts of epilepsy: a synopsis}

The writings on a Babylonian tablet from the British Museum and an Assyrian duplicate represent a missing chapter on epilepsy from a Babylonian textbook of medicine ${ }^{\star}$, the Sakikku, written around 1067-46 BC. ${ }^{1-3}$ Galen of Pergamon (AD 130-200) deduced that epilepsy was a brain disorder due to an accumulation of thick humours. ${ }^{4}$

Vesalius recognised focal epilepsy: “ . . .a certain aura or vapour . . .carried from the leg through the hip, then the scapula, upward to the head; then the left leg is agitated by the vehemence of the disease and convulsed ..." Willis observed that convulsions arose "most often from the head itself . . .the fault both of Blood sending, and of the Brain receiv-

* If in his fit he loses consciousness and foam comes from his mouth, it is miqtu. (cf major generalised fit) (If in his fit) he loses consciousness and his arms and legs bend round to the same side as his neck, it is miqtu. If at the end of his fit his limbs become paralysed . . . (cf Todd's palsy)

If before his fit a half of his body is "heavy" for him and pricks him ... (Jacksonian sensory aura)

If his seizure (or, possession) always takes place in the evening, it is the seizure of a ghost (nocturnal epilepsy). ... if he cries "My heart, my heart!", if he blinks his eyes, has hot flushes (?), rubs involuntarily the tip of his nose and the tips of his fingers and toes are cold; if he remains conscious but when you try to speak with him he acts strangely- hand of Lilu-la'bi. (autonomic disturbances and automatisms of complex partial (temporal lobe) fits). ing ... morbifick matter. ${ }^{6} \ldots$.. "The evil disposition of the brain is either hereditary or acquired." Injury, "prolonged intemperance", or chronic illness might initiate epilepsy. He described focal and spreading aurae.The mechanism was an "explosion", "transmitted into various parts of the nervous system ... as if grains of gunpowder were laid in a long train to be fired successively." - the kindling phenomenon anticipated.

\section{The nature of the epileptic phenomena}

Theories included excess phlegm in the brain; according to Paracelsus, a boiling up of the vital spirits (spiritus animalis). In the 17 th century Willis visualised an "explosion". A century later Marshall Hall talked of abnormal irritability in the afferent limb or central section of the reflex arc. However, the primary source was in the cervical cord, loss of consciousness in a fit being the result of secondary cerebral venous congestion. Brown-Séquard in 1858 ascribed an important role to peripheral afferent nerve irritability, and the medulla was the central component of the reflex mechanism. Reflex cerebral vasospasm, rather than cerebral venous congestion, was the cause of loss of consciousness.

continued on page 682 